\title{
Acute kidney Injury in Children: Impacts and its Management
}

\author{
Quddus ASMR ${ }^{1}$, Hasan MJ ${ }^{2}$
}

\begin{abstract}
The incidence of acute kidney injury (AKI) in children is increasing globally and is associated with increased mortality and long-term renal consequence. The definition of pediatric AKI was standardized for a more accurate assessment of the epidemiology of pediatric AKI. The definition of $A K I$ is based on elevation in serum creatinine levels or decrease inurine output; accordingly, epidemiological studies have ensued. Recent advances in leveraging electronic medical health record systems and newbiomarkers appear to detect $\mathrm{AKI}$ earlier and predict prognosis more accurately than traditional markers have allowed for real-time risk stratification and prevention of pediatric AKI in the hospital setting. For high risk or early stage AKI patients, avoidance of nephrotoxins, optimization of blood pressure and volume status, sufficient nutritional support are necessary and have been demonstrated tobe effective in preventing the occurrence of $\mathrm{AKI}$ and improving prognosis. Lastly, renal replacement therapy is needed when conservative care fails. Further therapeutic innovation willdepend on improving the understanding of the basic mechanisms underlying $\mathrm{AKI}$ in children.
\end{abstract}

CBMJ 2018 January: vol. 07 no. 01 P: 48-53

Keywords: Acute kidney injury, Critical care, Pediatrics \section{Introduction}

Kidney disease is now a global public health concern across the age spectrum, including in children. Acute kidney injury (AKI) (also referred to as acute renal failure) reflects a clinical presentations ranging from mild to severe injury that may result in permanent and complete loss of renal function. Acute kidney failure (AKF) in children is a catastrophic event. Acute kidney injury (AKI) can be defined as abrupt decline in renal excretory function, resulting in a decline in glomerular filtration rate (GFR), and impaired control of acid-base, electrolyte and fluid balance. Now AKI is a common problem, particularly in hospitalized children. The manifestation of $\mathrm{AKI}$ in children appears to be increasing and the etiology of AKI over the past decades has shifted from primary renal disease to multifactorial causes and it is an independent risk factor for increased mortality and severe morbidity. ${ }^{1-2}$

Renal injury can be divided into pre-renal disease, renal disease including vascular insults and post renal disease. The prognosis of AKF is highly dependent on the underlying etiology of the AKF. Children who suffered AKF from any cause are at risk of developing chronic kidney disease several years after the initial insult. ${ }^{2}$
Recently, many studies have been conducted in the field of pediatric AKI following adult studies and have prompted new interest.

\section{Definition of AKI}

There are several definitions have been used, most are based on the Risk, Loss of kidney function, Injury, Failure, End-stage renal disease (RIFLE) criteria, the subsequent pediatric RIFLE (pRIFLE) score and the Acute Kidney Injury Network (AKIN) criteria. Each of these definitions and stages for kidney injury slightly different, which made comparison studies and standardized recommendations regarding management more difficult. ${ }^{3}$ In 2012, a standardized definition of $\mathrm{AKI}$ was proposed by the

1. Prof. Dr. A.S.M. Ruhul Quddus; Professor (C.C), Department of Pediatrics, Community Based Medical College, Bangladesh

2. Dr. Mahmud Javed Hasan; Associate Professor and Head, Department of Nephrology Community Based Medical College, Bangladesh

\footnotetext{
Address of correspondence:

Email: ruhulquddush@gmail.com

Mobile: 01712123225
} 
Kidney Disease: Improving Global Outcomes (KDIGO) and has been validated in children and adults. ${ }^{4}$ All are based on increase in serum creatinine from an established baseline or by the development of oliguria. The bloomers of a serum creatinine-based definition for $\mathrm{AKI}$ are well recognized including the

- influence of non-glomerularfiltration rate (GFR) determinants (e.g., musclemass, diet, hydration status);

- lack of sensitivity to acute, small changes in renal function; and

- excretion by routes other than filtration (proximaltubular secretion and bacterial degradation in the gastrointestinal tract) ${ }^{17-18}$

The severity of AKI is staged according to the amplitude of serum creatinine elevation form baseline value or the duration of compromised urine output. For neonates, the neonatal modified KDIGO definition was used in a recent large group (Table 1). ${ }^{5-6}$ Even though it is based on a modification of the KDIGO definition, it is different with urinary output examine in $24 \mathrm{~h}$. In addition, the baseline value is the lowest previous serum creatinine level because it reflects maternal creatinine in the first few days, declines physiologically within weeks of life at a rate that varies with gestational age ${ }^{41}$

Table 1. Definitions and Staging of Kidney Disease: Improving Global Outcomes (KDIGO) and Neonatal Modified KDIGO Criteria for Acute Kidney Injury

\begin{tabular}{|c|c|c|c|c|}
\hline \multirow[t]{2}{*}{ Stage } & \multicolumn{2}{|c|}{ Pediatric KDIGO criteria } & \multicolumn{2}{|c|}{$\begin{array}{l}\text { Neonatal modified KDIGO } \\
\text { criteria }\end{array}$} \\
\hline & $\begin{array}{c}\text { Serum } \\
\text { creatinine }\end{array}$ & $\begin{array}{l}\text { Urine } \\
\text { Output }\end{array}$ & $\begin{array}{c}\text { Serum } \\
\text { creatinine }\end{array}$ & $\begin{array}{l}\text { Urine } \\
\text { output }\end{array}$ \\
\hline 1 & $\begin{array}{c}1.5-1.9 \text { times } \\
\text { baseline within } \\
7 \text { days }\end{array}$ & $\begin{array}{c}<0.5 \\
\mathrm{~mL} / \mathrm{kg} / \mathrm{h} \\
\text { for } 6-12 \\
\mathrm{~h}\end{array}$ & $\begin{array}{c}1.5-1.9 \text { times } \\
\text { baseline within } \\
7 \text { days }\end{array}$ & $\begin{array}{c}>0.5 \text { and } \\
\leq 1 \\
\mathrm{~mL} / \mathrm{kg} / \mathrm{h}\end{array}$ \\
\hline & OR & & OR & over $24 \mathrm{~h}$ \\
\hline & $\begin{array}{c}\geq 0.3 \mathrm{mg} / \mathrm{dL} \\
\text { increase within } \\
48 \mathrm{~h}\end{array}$ & & $\begin{array}{c}\geq 0.3 \mathrm{mg} / \mathrm{dL} \\
\text { increase within } \\
48 \mathrm{~h}\end{array}$ & \\
\hline 2 & $\begin{array}{c}2.0-2.9 \text { times } \\
\text { baseline }\end{array}$ & $\begin{array}{c}<0.5 \\
\mathrm{~mL} / \mathrm{kg} / \mathrm{h} \\
\text { for } \geq 12 \\
\mathrm{~h}\end{array}$ & $\begin{array}{c}2.0-2.9 \text { times } \\
\text { baseline }\end{array}$ & $\begin{array}{c}>0.3 \\
\text { and } \leq \\
0.5 \\
\mathrm{~mL} / \mathrm{kg} / \mathrm{h}\end{array}$ \\
\hline & & & & over $24 \mathrm{~h}$ \\
\hline
\end{tabular}

\begin{tabular}{|c|c|c|c|c|}
\hline \multirow[t]{2}{*}{ Stage } & \multicolumn{2}{|c|}{ Pediatric KDIGO criteria } & \multicolumn{2}{|c|}{$\begin{array}{l}\text { Neonatal modified } \\
\text { KDIGO criteria }\end{array}$} \\
\hline & Serum creatinine & $\begin{array}{l}\text { Urine } \\
\text { output }\end{array}$ & $\begin{array}{c}\text { Serum } \\
\text { creatinine }\end{array}$ & $\begin{array}{l}\text { Urine } \\
\text { output }\end{array}$ \\
\hline 3 & $\begin{array}{l}\geq 3.0 \text { times } \\
\text { baseline }\end{array}$ & $\begin{array}{c}<0.3 \\
\mathrm{~mL} / \mathrm{kg} / \mathrm{h} \\
\text { for } \geq 24 \mathrm{~h}\end{array}$ & $\begin{array}{l}\geq 3.0 \text { times } \\
\text { baseline }\end{array}$ & $\begin{array}{l}\leq 0.3 \\
\mathrm{~mL} / \mathrm{kg} / \mathrm{h} \\
\text { pver } 24 \mathrm{~h}\end{array}$ \\
\hline & OR & OR & \begin{tabular}{|l|} 
OR \\
\end{tabular} & \\
\hline & $\begin{array}{l}\text { Increase in serum } \\
\text { creatinine to }>4.0 \mathrm{mg} / \mathrm{dL} \\
\end{array}$ & $\begin{array}{c}\text { Anuria for } \\
\geq 12 \mathrm{~h}\end{array}$ & $\begin{array}{l}\text { Increase in serum } \\
\text { creatinine to } \geq 2.5 \mathrm{mg} / \mathrm{dL} \\
\end{array}$ & \\
\hline & OR & & OR & \\
\hline & $\begin{array}{l}\text { Initiation of renal } \\
\text { replacement therapy }\end{array}$ & & $\begin{array}{l}\text { Initiation of renal } \\
\text { replacement therapy }\end{array}$ & \\
\hline & OR & & & \\
\hline & $\begin{array}{c}\text { Decrease in eGFR } \\
\text { to }<35 \mathrm{~mL} / \mathrm{min} \text { per } \\
1.73 \mathrm{~m}^{2}\end{array}$ & & & \\
\hline
\end{tabular}

\section{Epidemiology}

In recent years, epidemiological data revealing the financial cost and high morbidity and mortality associated with AKI have been reported in several studies on the subject involving pediatric patients. ${ }^{8}$ However, contrasted with large scale adult epidemiologic studies, robust and broad based data in pediatrics is scanty.

In 2010, an epidemiological study involving a large number of pediatric patients was published, using the p-RIFLE for AKI diagnosis. $11 \%$ incidence of $A K I$ has been demonstrated in patients between 31 days and 21 years of age admitted to a PICU in a single US center. A subsequent multi-center study in the same country described the incidence of 3.9 cases $/ 1,000$ hospitalizations and there was a need for artificial renal support (ARS) in $8.8 \%$ of the cases. This study also demonstrated higher mortality in the group requiring ARS $27.1 \%$ versus $14.2 \% p<0.001)^{9}$ In an assessment at a single center in New Zealand in the period 2001-2006, involving 226 children aged 0-14 years submitted to RRT and reported a mortality rate of $11 \% .{ }^{10}$

Using the KDIGO classification available studies on the epidemiology of pediatric AKI in developing countries are mostly observational studies carried out in a single center. An exception is a study involving around 3.8 lac patients under the age of 18 years admitted to 27 Chinese hospitals, 
which reported an incidence of $A K I$ (AKIN) of $0.32 \%$ and a mortality rate of $3.4 \%$ in patients who developed AKI at any stage. ${ }^{11}$ Mortality rates of $41.5 \%, 50.4 \%$ and $30 \%$ showed in studies in Nigeria, India, Thailand and Pakistan respectively. ${ }^{12-1}$

The Assessment of Worldwide Acute Kidney Injury, Renal Angina, and Epidemiology (AWARE) study described epidemiology of AKI. One study demonstrated that AKI developed in $26.9 \%$ of patients and KDIGO stage 2 or $3 \mathrm{AKI}$ in $11.6 \%$ within 7 days of PICU admission. ${ }^{40}$ AWARE is such a vital study that will inform the nephrology community of the prevalence and associations of $\mathrm{AKI}$ in pediatric patients.

\section{Management and prevention of AKI}

\section{Risk factors:}

As there are no effective medications for established $\mathrm{AKI}$, prevention and early detection are the mainstays of management. Close monitoring of highrisk patients and reducing additional risk factors can prevent the occurrence of AKI. Prematurity and chronic diseases such as CKD render the patient susceptible to AKI and events such as volume depletion, exposure to nephrotoxins, sepsis, major surgery and critical illness lead to AKI. ${ }^{16}$

To predict AKI incritically ill children, the renal angina index was proposed on the basis of subtle kidney injury and patient risk factors such as ICU admission, stem cell transplantation, ventilation and inotropy. ${ }^{19}$ Recently, a system using electronic health records was implemented and helped physicians detect AKI early and mitigate the influence of risk factors. ${ }^{20}$ The system electronically reveals high-risk patients to the medical team in near real-time. As such, the medical team does not miss high-risk patients and monitors them carefully. It has been shown to improve the rate of recovery from AKI. ${ }^{21}$

For pediatric patients, this system was developed to screen children who experienced multiple nephrotoxin exposures, which prompted clinicians to monitor more closely for the development of AKI. It demonstrated a positive effect in decreasing exposure to multiple nephrotoxins and finally, AKI events. $^{22}$

\section{Supportive care}

The supportive care comprises optimization of volume status, avoidance of nephrotoxic agents, blood pressure and nutritional support. It is recommended to maintain adequate renal perfusion through fluid and hemodynamic management. ${ }^{23}$ Volume status should be optimal (i.e., not excessive, not insufficient). The previous medical cases and symptoms are important to evaluate volume status. Fluid intake, body weight,urine and stool output and vital signs should be monitored daily and lung sound and lower extremity edema should be checked.

In the acute phase, fluid accumulation is common in the PICU, which is associated with high mortality in critically ill patients. The pediatric literature suggests that 10$20 \%$ fluid overload is a critical threshold at which outcomes are negatively impacted. ${ }^{26-28}$

Again, hypervolemic patients require further fluid restriction, urine output, omitting the replacement of insensible fluid losses and extrarenal losses while considering adequate nutritional support. ${ }^{25}$ Diuretics therapy, especially loop diuretics, should be considered for hypervolemic patients. The pediatric literature shows that clinicians should consider initiating renal replacement therapy (RRT) at a fluid overload of $>20 \%$, while a fluid overload $10-20 \%$ requires further evaluation. ${ }^{28}$

It is crucial for a patient to maintain optimal blood pressure. For patients with hypotension, fluid resuscitation is initially considered if hypotension is due even partially to hypovolemia.

One of the most common causes of AKI in hospitalized children is Nephrotoxin exposure. ${ }^{30}$ Some well-known nephrotoxins are Amphotericin, aminoglycoside, vancomycin, nonsteroidal anti-inflammatory drugs, angiotensin-converting enzyme inhibitors, angiotensin receptor blockers, calcineurin inhibitors, cisplatin and methotrexate etc. ${ }^{29}$ Doctors must need to be balance the therapeutic benefits versus the 
risk for nephrotoxicity. If the use of nephrotoxic medications is mandatory, their dosage or dosing interval should be adjusted and monitored to reduce renal toxicity.

Nutritional support is crucial for improving outcomes in children with AKI. For ill children with $\mathrm{AKI}$, nutritional requirements should be individualized and frequently assessed. ${ }^{31}$

\section{Pharmacological treatment}

Many researchers conducted investigation regarding medications to prevent and treat AKI. Anti-inflammatory, anti-oxidative and anti-apoptotic interventions are representative examples; however, their yield remains insignificant. Although in certain situations, a few medications have demonstrated effectiveness, but most have yielded negative or conflicting results. The KDIGO guideline recommend NAC to prevent contrast-induced $\mathrm{AKI}$ in high-risk patients. ${ }^{4}$ However, two large, well-designed studies reported no benefit of $\mathrm{N}$ Acetylcysteine (NAC) in reducing the incidence of contrast- induced $\mathrm{AKI}^{32}$ Diuretics are not recommended for the prevention of $\mathrm{AKI}$ as their use does not alter outcomes in those with established AKI. It should be used only to control fluid overload. Low-dose dopamine and fenoldopam did not have a positive effect on protection against $\mathrm{AKI}^{33}$ To establish the basis for routine clinical use of new medications, additional multicenter, highquality trials must be considered.

\section{RRT and Dialysis}

RRT is required when conservative care fails. Children with AKI should be referred for renal replacement therapy (RRT) ${ }^{34}$ when they have refractory fluid overload, hyperkalaemia, hyponatraemia, uraemia or acidosis. Continuous hemofiltration/ diafiltraton and/or peritoneal dialysis (PD) are recommended for hemodynamically unstable children with AKI. Intermittent haemodialysis (HD) is suitable for haemodynamically stable patients given the risk of hypotension.

\section{Future perspective}

Recently, widely used renal function marker, creatinine, is restricted dueto its late increase in the course of AKI, and its susceptibility to changes by nonrenal factors, such as gender, age and muscle mass. ${ }^{36}$ In this regard, researchers have been searching new biomarkers that are rapid, sensitive, specific, inexpensive, noninvasive, and unaffected by clinical factors. Some of these are Cystatin C, neutrophil gelatinase-associated lipocalin (NGAL), kidney injury molecule-1, N-acetyl- D-glucosaminidase, interleukin-18, livertype fatty acid binding protein, cycle arrest markers. Among them, the most widely studied is NGAL. Using NGAL, after postoperative insult in cardiac surgeries in patients, sepsis and contrast use, showed good accuracy for the detection of $\mathrm{AKI}^{37}$ These biomarkers are appeared to detect AKI earlier and predict prognosis more accurately than serum creatinine levels. The concept of "Renal Angina" (RA) was also developed to improve the pre-test probability of available biomarkers in 2010, which have some special features that indicate risk for $\mathrm{AKI}$ and early clinical signs of renal damage.

The RA concept has been assessed in one large group of critically-ill adult patients. It showed a high sensitivity (92\%) associated with the development of AKI. ${ }^{39}$ For a better detection of renal angina,an assessment tool called the Renal Angina Index (RAI) has been developed in the pediatric population. To calculate the "Renal Angina Index" (RAI), it is defined by some factors that make the child susceptible to AKI, and early clinical signs of AKI (injury). Each characteristic assigns a score and the score obtained in "risk" is multiplied bythe score obtained in "injury", resulting in the RAI (Table 2).

Table 2. Renal Angina Index calculation.

\begin{tabular}{|l|c|c|}
\hline Risk factor & Risk & Score \\
\hline Pediatric ICU admission & Moderate & 1 \\
\hline Transplantation & High & 3 \\
\hline Ventilation and inotropy & Very High & 5 \\
\hline Decrease in CrCL & \%Fluid overload & \\
\hline$<0$ & $<0-5 \%$ & 1 \\
\hline $1,0-1,49 x$ & $5-9,99 \%$ & 2 \\
\hline $1,5-1,99 x$ & $10-14,99 \%$ & 4 \\
\hline
\end{tabular}


The RA probability assessment in AKI appears as good metrics both in children and adults; future research will need to adjust and recalibrate the RA concept, especially in combination with other AKI biomarkers.

\section{Conclusion}

Promising studies aimed into how best to define, predict, diagnose, assess, prevent, and manage the care of pediatric patients with $\mathrm{AKI}$ and mitigate its effects are still ongoing. Rapid progress over the past few yearshas brought the advances andit can be hoped that the field continues to expand and allow for improved treatment and prevention strategies in the future.

\section{References}

1. Alkandari $O$, Eddington $K A$, Hyder $A$, et al. Acute kidney injury is an independentrisk factor for pediatric intensive care unit mortality, longer length of stay andprolonged mechanical ventilation in critically ill children: a two-center retrospectivecohort study. Crit Care 2011;15:R146.

2. Yan Cao, Zhu-Wen Yi, Hui Zhang, et al. Etiologyand outcomes of acute kidney injuries in Chinese children: a prospective multi centre investigation. BMC Urology 2013; 13:41.

3. Sutherland SM, Byrnes JJ, Kothari M, et al. $A K I$ in hospitalized children: comparing the pRIFLE, AKIN, and KDIGO definitions. Clin J Am Soc Nephrol. 2015;10(4):554-561.

4. Kellum JA, Lameire N. Diagnosis, evaluation, and management of acute kidney injury: a KDIGO summary (Part 1). Crit Care 2013; 17:204.

5. Charlton JR, Boohaker L, Askenazi D, Brophy $P D$, D'Angio $C$, Fuloria $M$, et al. Incidence and Risk Factors of Early Onset Neonatal AKI. Clin J Am Soc Nephrol 2019;14:184-95.

6. Jetton JG, Boohaker LJ, Sethi SK, Wazir S, Rohatgi S, Soranno DE, et al. Incidence and outcomes of neonatal acute kidney injury (AWAKEN): a multicentre, multinational, observational cohort study. Lancet Child Adolesc Health 2017;1:184-94.

7. Newman DJ, Prize CP. Renal function. In: Burtis CA, Ashwood ER, editors. Tietz Textbook of Clinical Chemistry. Philadelphia: WB Saunders Company; 1999. p. 1241-6. Back to cited text no. 17
8. Lewington AJ, Cerdá J, Mehta RL. Raising awareness of acutekidney injury: a global perspective of a silent killer. Kidney Int. 2013;84:457-67.

9. Sutherland SM, Ji J, Sheikhi FH, Widen E, Tian L, Alexander SR, etal. AKI in hospitalized children: epidemiology and clinical associationsin a national cohort. Clin J Am Soc Nephrol. 2013;8:1661-9.

10. Ball EF, Kara T. Epidemiology and outcome of acute kidney injuryin New Zealand children. J Paediatr Child Health 2008;44:642-6.

11. Cao Y, Yi ZW, Zhang $H$, Dang XQ, Wu XC, Huang AW. Etiology and outcomes of acute kidney injury in Chinese children: a prospective multicentre investigation. BMC Urol 2013;13:41.

12. Vachvanichsanong $P$, Dissaneewate $P, \operatorname{Lim} A$, McNeil E. Childhood acute renal failure: 22year experience in a university hospital in southern Thailand. Pediatrics 2006;118:e786-

91.

13. Olowu WA. Acute kidney injury in children in Nigeria. Clin Nephrol. 2015;83:70-4.

14. Tresa V, Yaseen A, Lanewala AA, Hashmi S, Khatri S, Ali I, et al. Etiology, clinical profile and short-term outcome of acute kidney injury in children at a tertiary care pediatric nephrology center in Pakistan. Ren Fail 2017;39:26-31.

15. Rustagi RS, Arora K, Das RR, Pooni PA, Singh $D$. Incidence, risk factors and outcome of acute kidney injury in critically ill children a developing country perspective. PaediatrInt Child Health 2017;37:35-41.

16. Sutherland SM, Chawla LS, Kane-Gill SL, Hsu RK, Kramer AA, Goldstein SL, et al. Utilizing electronic health records to predict acute kidney injury risk and outcomes: workgroup statements from the 15(th) ADQI Consensus Conference. Can J Kidney Health Dis 2016;3:11.

17. Mitch WE, Walser M. A proposed mechanism for reduced creatinine excretion in severe chronic renal failure. Nephron. 1978;21(5):248-54.

18. Dunn SR, Gabuzda GM, Superdock KR, Kolecki RS, Schaedler RW, Simenhoff ML. Induction of creatininase activity in chronic renal failure: timing of creatinine degradation and effect of antibiotics. Am J Kidney Dis. 1997;29(1):72-7.

19. Basu RK, Zappitelli M, Brunner L, Wang Y, Wong HR, Chawla LS, et al. Derivation and validation of the renal angina index to improve the prediction of acute kidney injury 
in critically ill children.Kidney Int 2014;85:65967.

20. Sutherland SM, Chawla LS, Kane-Gill SL, Hsu RK, Kramer AA,Goldstein SL, et al. Utilizing electronic health records to predict acute kidney injury risk and outcomes: workgroup statements from the 15(th) ADQI Consensus Conference. Can J Kidney HealthDis 2016;3:11.

21. Park S, Baek SH, Ahn S, Lee KH, Hwang H, Ryu J, et al. Impact of Electronic Acute Kidney Injury (AKI) Alerts With Automated Nephrologist Consultation on Detection and Severity of AKI: AQuality Improvement Study. Am J Kidney Dis 2018;71:9-19.

22. Goldstein SL, Kirkendall E, Nguyen $H$, Schaffzin JK, Bucuvalas J, Bracke T, et al. Electronic health record identification of nephrotoxin exposure and associated acute kidney injury. Pediatrics. 2013;132:e756-67.

23. Chen H, Busse LW. Novel Therapies for Acute Kidney Injury. Kidney Int Rep 2017;2:785-99.

24. Devarajan P. Acute Kidney Injury. In: Kliegman RM, ST Geme IIIJW, Blum NJ, Shah SS, Tasker RC, Wilson KM, et al., editors. Nelson Textbook of Pediatrics. 21 ed. Philadelphia: Elsevier, 2019:2769-74.

25. Claure-Del Granado R, Mehta RL. Fluid overload in the ICU: evaluation and management. BMC Nephrol 2016;17:109.

26. Wang $N$, Jiang $L$, Zhu B, Wen Y, Xi XM. Fluid balance and mortalityin critically ill patients with acute kidney injury: a multicenter prospective epidemiological study. Crit Care 2015;19:371.

27. Sutherland SM, Zappitelli M, Alexander SR, Chua AN, Brophy PD, Bunchman TE, et al. Fluid overload and mortality in children receiving continuous renal replacement therapy: the prospective pediatric continuous renal replacement therapy registry. Am J Kidney Dis 2010;55:316-25.

28. Selewski DT, Goldstein SL. The role of fluid overload in the prediction of outcome in acute kidney injury. Pediatr Nephrol 2018;33:13-24.

29. Cho MH, Kang HG. Acute kidney injury and continuous renal replacement therapy in children; what pediatricians need to know. Korean J Pediatr 2018;61:339-47.

30. Hui-Stickle S, Brewer ED, Goldstein SL. Pediatric ARF epidemiology at a tertiary care center from 1999 to 2001. Am J Kidney Dis2005;45:96-101.
31. Sethi SK, Maxvold N, Bunchman T, Jha P, Kher $V$, Raina $R$. Nutritional management in the critically ill child with acute kidney injury: a review. Pediatr Nephrol 2017;32:589-601.

32. Weisbord SD, Gallagher M, Jneid H, Garcia $S$, Cass A, Thwin SS, etal. Outcomes after Angiography with Sodium Bicarbonate and Acetylcysteine. N Engl J Med 2018;378:60314.

33. Karthik S, Lisbon A. Low-dose dopamine in the intensive careunit. Semin Dial 2006;19:465-71.

34. Ronco C, Ricci Z, De Backer D, et al. Renal replacement therapy in acute kidney injury: controversy and consensus. Critical Care 2015; 19(1):146.

35. VA/NIH Acute Renal Failure Trail Network Palevsky PM, Zhang JH, et al. Intensity of renal support in critically ill patients with acute kidney injury. New England Journal of Medicine 2008; 359:7-20.

36. Ciccia E, Devarajan P. Pediatric acute kidney injury: prevalence, impactand management challenges. Int J Nephrol Renovasc Dis 2017;10:77-84.

37. Zhou F, Luo Q, Wang L, Han L. Diagnostic value of neutrophil gelatinase-associated lipocalin for early diagnosis of cardiac surgery-associated acute kidney injury: a meta-analysis. Eur J Cardiothorac Surg. 2016;49:746-55.

38. Chawla LS, Goldstein SL, Kellum JA, Ronco C. Renal angina: conceptand development of pretest probability assessment in acute kidney injury. Crit Care 2015;19:93.

39. Cruz DN, Ferrer-Nadal A, Piccinni $P$, et al. Utilization of small changes in serum creatinine with clinical risk factors to assess the risk of AKI in critically III adults. Clin J Am Soc Nephrol. 2014;9:663-672.

40. Kaddourah A, Basu RK, Bagshaw SM, Goldstein SL. Epidemiology of Acute Kidney Injury in Critically III Children and Young Adults. N Engl J Med 2017;376:11-20.

41. Siegel SR, Oh W. Renal function as a marker of human fetal maturation. Acta Paediatr Scand. 1976;65:481-5. 